\title{
PRECISION GAMMA RAY ENERGIES IN THE ENERGY INTERVAL BETWEEN 45 AND 1275 keV*
}

\author{
D. E. RAESIDE
}

Physics Department, The University of Michigan, Ann Arbor, Michigan 48104, U.S.A.

Received I June 1970

Curved-crystal spectrometers have been utilized to obtain measurements of more than forty gamma ray energies in the energy interval between 45 and $1275 \mathrm{keV}$ for nuclei with

\section{Experimental arrangements}

Two curved-crystal spectrometers and three curvedcrystals were utilized in obtaining the gamma ray energy measurements reported in this paper. A description of the design of the spectrometers and the various experimental techniques associated with their use has been given elsewhere ${ }^{1.2}$ ). All three crystals were bent to a $2 \mathrm{~m}$ radius and the characterizations of the crystals were as follows: $\mathrm{Ge}(022), \mathrm{Ge}(400)$ and $\mathrm{Q}(310)$. The energy resolutions of the three crystals were about equal for a given source width. For the most frequently used source width the best crystal had an energy resolution given by $\Delta E(\mathrm{fwhm})=2.2 \times 10^{-5}\left(E^{2} / n\right)$, where $n$ is the order of reflection and $E$ is the gamma ray energy in $\mathrm{keV}$ while the poorest crystal had an energy resolution which was about $20 \%$ greater. The $\mathrm{Ge}(022)$ and $\mathrm{Ge}(400)$ crystals were calibrated using the $411.794 \pm 0.008 \mathrm{keV}$ gamma ray occurring in the decay of ${ }^{198} \mathrm{Au}^{3-5}$ ), while the $\mathrm{Q}(310)$ crystal was calibrated using the $59.31918 \pm 0.00035 \mathrm{keV} \mathrm{K} \alpha_{1} \mathrm{X}$-ray of tungsten accompanying the decay of ${ }^{182} \mathrm{Ta}^{4-6}$ ).

All samples were produced in the University of Michigan Ford nuclear reactor (thermal neutron flux $\sim 10^{13}$ neutrons $/ \mathrm{sec} \cdot \mathrm{cm}^{2}$ ). Several of the samples were fabricated using enriched isotopes obtained from Oak Ridge National Laboratory. These enriched isotopes and their enrichments were as follows: ${ }^{151} \mathrm{Eu}(96.8 \%), \quad{ }^{152} \mathrm{Sm}(99.2 \%), \quad{ }^{153} \mathrm{Eu}(98.8 \%)$, ${ }^{190} \mathrm{Os}(95.5 \%)$ and ${ }^{192} \mathrm{Os}(98.7 \%)$.

Measurements were taken in the highest order permitted by gamma ray intensity and counting time. All final energy values are the average of the values obtained in several runs.

\section{Results and discussion}

The results of the present investigation are given in table 1. A discussion of these results and the results of previous investigators is given below.

\footnotetext{
* This work was supported in part by the U.S. Atomic Energy Commission.
}

$109 \leqslant A \leqslant 193$. Many of these energy measurements have sufficiently small uncertainties associated with them to make them useful for the calibration of $\mathrm{Ge}(\mathrm{Li})$ spectra.

${ }^{109} \mathrm{Cd}$ : No measurement of the energy of the $88 \mathrm{keV}$ gamma ray occurring in the decay of ${ }^{109} \mathrm{Cd}$ utilizing a curved-crystal spectrometer has been reported as yet. The measurement given in table 1 was performed in this laboratory by Diethrich ${ }^{7}$ ). His value of 88.035 $\pm 0.006 \mathrm{keV}$ is in agreement with five of the seven recent values given in table 2 and has an uncertainty associated with it which is smaller than any of the uncertainties assigned to these previous measurements.

${ }^{152} \mathrm{Eu}$ : The energies of several of the gamma rays associated with the decay of ${ }^{152}$ Eu have been measured previously with curved-crystal spectrometers ${ }^{14-18}$ ). These measurements are summarized in table 3 . Precision measurements of the energies of the ${ }^{152} \mathrm{Eu}$ gamma rays have also been made using other spectrometers and table 4 shows a comparison between the values obtained by two groups and those of the present work.

${ }^{153} \mathrm{Sm}$ : All of the ${ }^{153} \mathrm{Sm}$ gamma rays which we investigated have been investigated previously with curvedcrystal spectrometers ${ }^{18,22-27}$ ). A summary of the results obtained in previous investigations is given in table 5 . In addition, a precision measurement of the energy of the gamma ray de-exciting the $97 \mathrm{keV}$ level of ${ }^{153} \mathrm{Eu}$ has been made using a $\mathrm{Ge}(\mathrm{Li})$ spectrometer by Greenwood et al. ${ }^{5}$ ). Their result is $97.432 \pm 0.005 \mathrm{keV}$.

${ }^{154} \mathrm{Eu}$ : Two of the gamma rays associated with the $\overline{\text { decay }}$ of ${ }^{154} \mathrm{Eu}$ have been studied previously with curved-crystal spectrometers ${ }^{15,18}$ ). Table 6 lists previously obtained results. The most complete sets of precision measurements of ${ }^{154} \mathrm{Eu}$ gamma ray energies previously reported are given by Aubin et al. ${ }^{19}$ ) and Meyer $\left.^{28}\right)$. Both of these investigations utilized $\mathrm{Ge}(\mathrm{Li})$ spectrometers. In table 7 we show a comparison between the results of these studies and those of the present study. As a part of the present investigation we have made an effort to measure the energies of several weak low energy gamma rays reported by $\mathrm{Meyer}^{28}$ ). 
D. E. RAESIDE

TABLE 1

Precision gamma ray energies in the energy interval between 45 and $1275 \mathrm{keV}$ for nuclei with $109 \leqslant A \leqslant 193$.

\begin{tabular}{|c|c|}
\hline Parent nucleus & Gamma ray energy (keV) \\
\hline${ }^{109} \mathrm{Cd}$ & $88.035 \pm 0.006$ \\
\hline${ }^{152} \mathrm{Eu}$ & $\begin{array}{l}121.780 \pm 0.004 \\
244.693 \pm 0.010 \\
295.934 \pm 0.038 \\
344.267 \pm 0.010 \\
411.071 \pm 0.032 \\
443.924 \pm 0.085\end{array}$ \\
\hline${ }^{153} \mathrm{Sm}$ & $\begin{array}{c}54.1988 \pm 0.0022 \\
69.6715 \pm 0.0020 \\
75.4212 \pm 0.0023 \\
83.3666 \pm 0.0024 \\
89.4853 \pm 0.0033 \\
97.4292 \pm 0.0033 \\
103.179 \pm 0.004\end{array}$ \\
\hline${ }^{154} \mathrm{Eu}$ & $\begin{array}{ll}123.070 \pm 0.004 \\
131.570 \pm 0.035 \\
146.035 \pm 0.025 \\
156.31 \pm 0.10 \\
188.246 \pm 0.013 \\
247.939 \pm 0.008 \\
444.443 \pm 0.073 \\
581.91 \pm 0.11 \\
591.814 \pm 0.038 \\
692.48 \pm 0.15 \\
723.430 \pm 0.075 \\
756.919 \pm 0.062 \\
873.236 \pm 0.076 \\
996.00 \pm 0.22 \\
1004.57 \pm 0.18 \\
1274.69 \pm 0.06\end{array}$ \\
\hline${ }^{155} \mathrm{Eu}$ & $\begin{array}{r}45.2972 \pm 0.0013 \\
57.9805 \pm 0.0020 \\
60.0100 \pm 0.0018 \\
86.0621 \pm 0.0051 \\
86.5452 \pm 0.0033 \\
105.308 \pm 0.003\end{array}$ \\
\hline${ }^{156} \mathrm{Eu}$ & $\begin{array}{c}88.9637 \pm 0.0024 \\
199.214 \pm 0.012\end{array}$ \\
\hline${ }^{170} \mathrm{Tm}$ & $84.2572 \pm 0.0026$ \\
\hline${ }^{191} \mathrm{Os}$ & $\begin{aligned} 82.4272 & \pm 0.0099 \\
129.431 & \pm 0.005\end{aligned}$ \\
\hline${ }^{193} \mathrm{Os}$ & $138.947 \pm 0.008$ \\
\hline
\end{tabular}

TABLE 2

Recent precision measurements of the energy of the $88 \mathrm{keV}$ gamma ray occurring in the decay of ${ }^{109} \mathrm{Cd}$.

\begin{tabular}{cl}
\hline Reference & Gamma ray energy (keV) \\
\hline 5 & $88.036 \pm 0.008$ \\
8 & $88.041 \pm 0.087$ \\
9 & $88.05 \pm 0.05$ \\
10 & $88.033 \pm 0.042$ \\
11 & $88.09 \pm 0.03$ \\
$12^{*}$ & $88.008 \pm 0.042$ \\
13 & $88.21 \pm 0.03$ \\
\hline
\end{tabular}

* The value quoted can be found in footnote 14 of ref. 12 .

TABLE 3

Previous measurements of the energies of gamma rays occurring in the decay of ${ }^{152} \mathrm{Eu}$ using curved-crystal spectrometers.

\begin{tabular}{|c|c|}
\hline Reference & Gamma ray energy (keV) \\
\hline 14 & $\begin{array}{l}121.779 \pm 0.006 \\
344.24 \pm 0.05\end{array}$ \\
\hline 15 & $\begin{array}{l}121.79 \pm 0.03 \\
244.84 \pm 0.20 \\
344.37 \pm 0.60\end{array}$ \\
\hline 16 & $121.78 \pm 0.05$ \\
\hline 18 & $\begin{array}{l}122.31 \pm 0.04^{*} \\
244.64 \pm 0.08 \\
344.34 \pm 0.23\end{array}$ \\
\hline
\end{tabular}

* A revised value for the $122 \mathrm{keV}$ gamma ray is given in ref. 15; it is quoted as $121.87 \pm 0.06 \mathrm{keV}$.

TABLE 4

A comparison of measurements of the energies of ${ }^{152} \mathrm{Eu}$ gamma rays (units: $\mathrm{keV}$ ).

\begin{tabular}{ccc} 
This work & Ref. 19 & Ref. 20 \\
\hline & & \\
\hline & & \\
$241.780 \pm 0.004$ & $121.78 \pm 0.03$ & $121.77 \pm 0.01$ \\
$295.934 \pm 0.038$ & $244.66 \pm 0.03$ & $244.68 \pm 0.02$ \\
$344.267 \pm 0.010$ & $344.31 \pm 0.03$ & $344.27 \pm 0.03$ \\
$411.071 \pm 0.032$ & $411.13 \pm 0.05$ & $411.12 \pm 0.06$ \\
$443.924 \pm 0.085$ & $443.98 \pm 0.05$ & $443.96 \pm 0.10$ \\
\hline
\end{tabular}


We were able to make energy measurements on three of these gamma rays and were able to detect the presence of a forth one, but we were not able to find any evidence for three of these weak gamma rays (table 8).

${ }^{155} \mathrm{Eu}:$ All of the ${ }^{155} \mathrm{Eu}$ gamma rays which we have

\section{TABLE 5}

Previous measurements of the energies of gamma rays occurring in the decay of ${ }^{153} \mathrm{Sm}$ using curved-crystal and beta spectrometers.

\begin{tabular}{cc}
\hline Reference & \\
& Gamma ray energy $(\mathrm{keV})$ \\
18 & $103.27 \pm 0.02$ \\
21 & $69.672 \pm 0.006$ \\
22 & $69.66 \pm 0.02$ \\
& $103.18 \pm 0.04$ \\
23 & $69.66 \pm 0.02$ \\
& $97.42 \pm 0.04$ \\
& $103.17 \pm 0.04$ \\
& $103.175 \pm 0.004$ \\
24 & $69.675 \pm 0.002$ \\
& $103.181 \pm 0.003$ \\
& $69.676 \pm 0.007$ \\
& $103.180 \pm 0.010$ \\
& $54.19 \pm 0.02$ \\
& $69.68 \pm 0.01$ \\
& $75.43 \pm 0.01$ \\
& $83.37 \pm 0.02$ \\
& $89.49 \pm 0.02$ \\
& $97.45 \pm 0.02$ \\
& $103.19 \pm 0.02$ \\
& \\
&
\end{tabular}

\section{TABLE 6}

Previous measurements of the energies of gamma rays occurring in the decay of ${ }^{154} \mathrm{Eu}$ using curved-crystal and beta spectrometers.

Reference Gamma ray energy $(\mathrm{keV})$

$\begin{array}{ll}15 & 123.07 \pm 0.04 \\ & 248.08 \pm 0.15 \\ 17 & 123.06 \pm 0.03 \\ 18 & 123.54 \pm 0.09^{*}\end{array}$

* A revised value is given in ref. 15 ; it is quoted as $123.21 \pm$ $\pm 0.04 \mathrm{keV}$. studied have been studied previously with curvedcrystal spectrometers ${ }^{15,29}$ ). A summary of the results obtained in these previous investigations is given in table 9. The two measurements reported by Alexander ${ }^{29}$ ) were reported without any estimation of the uncertainties associated with them.

\section{TABLE 7}

A comparison of measurements of the energies of ${ }^{154} \mathrm{Eu}$ gamma rays (units: $\mathrm{keV}$ ).

\begin{tabular}{crr}
\hline This work & \multicolumn{1}{c}{ Ref. 19} & \multicolumn{1}{c}{ Ref. 28} \\
\hline & & \\
$123.070 \pm 0.004$ & $123.10 \pm 0.03$ & $123.14 \pm 0.04$ \\
$247.939 \pm 0.008$ & $247.92 \pm 0.03$ & $248.04 \pm 0.04$ \\
$444.443 \pm 0.073$ & $444.34 \pm 0.07$ & $444.40 \pm 0.05$ \\
$591.814 \pm 0.038$ & $591.71 \pm 0.04$ & $591.74 \pm 0.05$ \\
$692.48 \pm 0.15$ & $692.42 \pm 0.06$ & $692.41 \pm 0.05$ \\
$723.430 \pm 0.075$ & $723.27 \pm 0.04$ & $723.30 \pm 0.04$ \\
$756.919 \pm 0.062$ & $756.82 \pm 0.05$ & $756.87 \pm 0.05$ \\
$873.236 \pm 0.076$ & $873.21 \pm 0.05$ & $873.19 \pm 0.05$ \\
$996.00 \pm 0.22$ & $996.30 \pm 0.05$ & $996.32 \pm 0.04$ \\
$1004.57 \pm 0.18$ & $1004.78 \pm 0.05$ & $1004.76 \pm 0.04$ \\
$1274.69 \pm 0.06$ & $1274.42 \pm 0.05$ & $1274.45 \pm 0.09$ \\
\hline
\end{tabular}

TABLE 8

Results of investigation of some weak low energy ${ }^{154} \mathrm{Eu}$ gamma rays reported by Meyer $^{28}$ ).

\begin{tabular}{cc}
$\begin{array}{c}\text { Energy (relative intensity) } \\
\text { Ref. } 28\end{array}$ & $\begin{array}{c}\text { Energy } \\
\text { This work }\end{array}$ \\
\hline $125.39 \mathrm{keV}(70)$ & not observed \\
$128.4 \mathrm{keV}(\leqslant 100)$ & not observed \\
$129.5 \mathrm{keV}(140)$ & not observed \\
$131.58 \mathrm{keV}(110)$ & $131.570 \pm 0.035 \mathrm{keV}$ \\
$134.84 \mathrm{keV}(72)$ & observed; too weak to measure \\
$146.05 \mathrm{keV}(260)$ & $146.035 \pm 0.025 \mathrm{keV}$ \\
$156.19 \mathrm{keV}(100)$ & $156.31 \pm 0.10 \mathrm{keV}$ \\
\hline
\end{tabular}

TABLE 9

Previous measurements of the energies of gamma rays occurring in the decay of ${ }^{155} \mathrm{Eu}$ using a curved-crystal spectrometer.

\begin{tabular}{rr}
15 & $45.29 \pm 0.01$ \\
& $60.00 \pm 0.02$ \\
& $86.54 \pm 0.01$ \\
& $105.32 \pm 0.03$ \\
& \\
& 58.00 \\
& 86.05 \\
\hline
\end{tabular}


TABLE 10

Previous measurements of the energies of gamma rays occurring in the decay of ${ }^{156} \mathrm{Eu}$ using curved-crystal spectrometers.

\begin{tabular}{cc}
\hline Reference & Gamma ray energy (keV) \\
& \\
\hline \multirow{2}{*}{15} & $88.97 \pm 0.01$ \\
& $199.19 \pm 0.06$ \\
& $88.967 \pm 0.002$ \\
& $199.216+0.005$ \\
& $88.974+0.011$ \\
& $199.24 \pm 0.05$ \\
\end{tabular}

TABLE 11

Previously reported measurements of the energy of the $139 \mathrm{keV}$ gamma ray occurring in the decay of ${ }^{193} \mathrm{Os}$.
Reference Gamma ray energy (keV)

$\begin{array}{ll}32 & 138.96 \pm 0.02 \\ 33 & 138.887 \pm 0.007 \\ 34 & 138.95 \pm 0.05 \\ 35 & 138.92 \pm 0.05\end{array}$

${ }^{156} \mathrm{Eu}$ : Both of the ${ }^{156} \mathrm{Eu}$ gamma rays which we have studied have been previously studied with curvedcrystal spectrometers and the previous results are presented in table $10^{15,25,30}$ ).

${ }^{170} \mathrm{Tm}$ : Measurements of the energy of the $84 \mathrm{keV}$ gamma ray occurring in the decay of ${ }^{170} \mathrm{Tm}$ using curved-crystal spectrometers have been made by other groups. Day ${ }^{31}$ ) reported a value of $84.229 \pm 0.041 \mathrm{keV}$. Hatch and Boehm ${ }^{15}$ ) obtained a value of $84.26 \pm$ $\pm 0.01 \mathrm{keV}$, and Marklund and Lindström ${ }^{14}$ ) give a value of $84.262 \pm 0.004 \mathrm{keV}$.

${ }^{191}$ Os: There have been no reported curved-crystal spectrometer studies of the gamma rays accompanying the decay of ${ }^{191}$ Os. Mazets and Sergeenkov ${ }^{32}$ ) have measured the energies of the same two gamma rays that we have studied. They utilized a prism-type beta spectrometer and obtained the following results: $82.52 \pm 0.03 \mathrm{keV}$ and $129.41 \pm 0.01 \mathrm{keV}$.

${ }^{193}$ Os: No curved-crystal spectrometer measurement of the energy of the $139 \mathrm{keV}$ gamma ray occurring in the decay of ${ }^{193}$ Os has been reported previously. Several energy measurements using beta spectrometers have been obtained, however, and these results are given in table $11^{32-33}$ ).

The author would like to take this opportunity to thank Professors J. J. Reidy and M. L. Wiedenbeck for their interest in this work, and P. L. Gardulski for his assistance with data collection for one of the samples.

\section{Note added in proof}

A study of the gamma rays associated with the decay of ${ }^{165}$ Dy has recently been undertaken in this laboratory by Ludington ${ }^{36}$ ). His curved-crystal spectrometer measurements for five of the strong transitions are as follows: $94.692 \pm 0.003 \mathrm{keV}, 279.759 \pm 0.015 \mathrm{keV}$, $361.670 \pm 0.018 \mathrm{keV}, \quad 633.432 \pm 0.060 \mathrm{keV}$ and $715.345 \pm 0.076 \mathrm{keV}$.

\section{References}

1) E. J. Seppi, H. Henrikson, F. Boehm and J. W. M. DuMond, Nucl. Instr. and Meth. 16 (1962) 17.

2) J. J. Reidy and M. L. Wiedenbeck, Nucl. Instr. and Meth.33 (1965) 213.

3) G. Murray, R. L. Graham and J. S. Geiger, Nucl. Phys. 63 (1965) 353.

4) B. N. Taylor, W. H. Parker and D. N. Langenberg, Rev. Mod. Phys. 41 (1969) 375.

5) R. C. Greenwood, R. G. Helmer and R. J. Gehrke, Nucl. Instr. and Meth. 77 (1970) 141.

6) J. A. Bearden, Rev. Mod. Phys. 39 (1967) 78.

7) C. G. Diethrich, Ph. D. Dissertation (University of Michigan, 1967).

8) F. J. Schima and J. M. R. Hutchinson, Nucl. Phys. A102 (1967) 667.

9) J. Libert, Nucl. Phys. A102 (1967) 477.

10) W. R. Pierson and R. H. Marsh, Nucl. Phys. A 104 (1967) 511.

11) C. Foin, A. Gizon and J. Oms, Nucl. Phys. A113 (1968) 241.

12) M. S. Freedman, F, T. Porter and F. Wagner, Phys. Rev. 151 (1966) 886.

13) T. Furuta and J. R. Rhodes, Intern. J. Appl. Rad. Isotopes 19 (1968) 483.

14) I. Marklund and B. Lindström, Nucl. Phys. 40 (1963) 329.

15) E. N. Hatch and F. Boehm, Z. Physik 155 (1959) 609.

16) I. Marklund, Nucl. Phys. 9 (1958/59) 83.

17) V. A. Romanov, Izvest. Akad. Nauk SSSR Ser. Fiz. 22 (1958) 191.

18) B. Andersson, Proc. Phys. Soc. A69 (1956) 415.

19) G. Aubin, J. Barrette, M. Barrette and S. Monaro, Nucl. Instr. and Meth. 76 (1969) 93.

20) G. Malmsten, O. Nilson and I. Andersson, Arkiv Fysik 33 (1966) 361.

21) T. Suter, P. Reyes-Suter, S. Gustafsson and I. Marklund, Nucl. Phys. 29 (1962) 33.

22) O. Beckman, Nucl. Instr. 3 (1958) 27.

23) T. J. Walters, J. H. Webber, N. C. Rasmussen and H. Mark, Nucl. Phys. 15 (1960) 653. 
24) P. Bergvall, Arkiv Fysik 17 (1960) 125.

25) O. W. B. Schult, Z. Naturforsch. 16a (1961) 927.

26) R. Hardell and S. Nilsson, Nucl. Phys. 39 (1962) 286.

27) P. Alexander, Phys. Rev. 134 (1964) B499.

28) R. A. Meyer, Phys. Rev. 170 (1968) 1089.

29) P. Alexander, Nucl. Phys. A108 (1968) 145.

30) J. T. Wasson, Z. Naturforsch. 15a (1960) 276.

31) P. P. Day, Phys. Rev. 102 (1956) 1572.

32) E. P. Mazets and Y. V. Sergeenkov, Izvest. Akad. Nauk Ser.
Fiz. 30 (1966) 1193.

33) R. H. Price, M. W. Johns, N. M. Ahmed and E. E. Habid, Can. J. Phys. 47 (1969) 727.

34) Z. Plajner, V. Brabec, L. Maly and M. Vejs, Nucl. Phys. A121 (1968) 367.

35̃) C. R. Cothern, H. J. Hennecke, J. C. Manthuruthil and R. C. Lange, Phys. Rev. 182 (1969) 1286.

36) M. A. Ludington, private communication. 